\title{
Health behaviors among testicular cancer survivors
}

\author{
Matthew J Reilley, MD, ${ }^{\mathrm{a}}$ Linda A Jacobs, PhD, RN, ${ }^{\mathrm{b}}$ David J Vaughn, MD, ${ }^{\mathrm{b}}$ and Steven $\mathrm{C}$ \\ Palmer, $\mathrm{PhD}^{\mathrm{b}}$
}

${ }^{a}$ Hospital of the University of Pennsylvania, Philadelphia, and ${ }^{b}$ Abramson Cancer Center, University of Pennsylvania, The Perelman Center for Advanced Medicine, Philadelphia

\begin{abstract}
Background With modern treatment, more than $95 \%$ of American men who are diagnosed with testicular cancer will be cured. Although there is growing evidence that these individuals may face heightened risk of cardiovascular disease after chemotherapy, there is a paucity of research to objectively classify health-promoting behaviors in this population and to identify the barriers to improving their health behaviors.

Objectives To identify health behavior patterns in a group of testicular cancer survivors (TCSs) and the barriers to more positive health behaviors and to examine the relationship between barriers, health behaviors, and quality of life (QOL).

Methods TCSs from the Pennsylvania State Cancer Registry who had been diagnosed during 1990-2005 completed a comprehensive survey about QOL, health behaviors, and barriers to optimal healthy behaviors. QOL, health behaviors, and the barriers were assessed for 189 respondents.

Results Smoking (25\%), risky drinking (35\%), elevated body-mass index (83\%), poor diet (95\% did not meet the guidelines for fruit and vegetable intake), and inadequate exercise $(50 \%)$ were common. Barriers to achieving optimal health behaviors were categorized as either cancer-related or competing demands. Cancer-related barriers contributed to worse physical QOL, whereas competing demands related to worse mental-health-related QOL.

Limitations Our sample size was moderate and self-selected. In addition, we used self-reports rather than the more standardized observation or interview-based data collection.

Conclusion TCSs demonstrate behaviors that put them at increased risk for future cardiovascular disease and complications.

Interventions aimed at reducing tobacco and risky alcohol use and improving dietary and physical activity levels are needed.

Funding/sponsorship NCl grant number 1R03CA124217; the Livestrong Foundation.

Disclosures The authors have no disclosures.
\end{abstract}

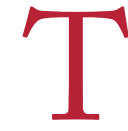

esticular cancer (TC) is the most common solid tumor diagnosed among men aged between 15 and 34 years, with about 8,000 cases being diagnosed in the United States each year. ${ }^{1}$ Moreover, men with TC are cured at rates of more than $95 \%$ with modern therapy, ${ }^{2}$ and there is now a growing population of testicular cancer survivors (TCSs) who live long lives without recurrence of their original cancer. Treatments for TC, however, are not without consequences. In particular, there is increasing evidence that TCSs experience increased risk for cardiovascular disease. ${ }^{3-5}$ The National Cancer Institute noted in a 2010 report on testicular cancer survivorship ${ }^{6}$ that healthy behaviors (smoking cessation, improving diet, and exercise) can play a significant role in attenuating many of these effects and can serve as targets for future interventions aimed at risk reduction.

In addition to radical orchiectomy, platinumbased chemotherapies may be crucial for cure in about $20 \%$ of patients with TC. Yet the long-term consequences of treatment with platinum-based agents are not well characterized. Cardiovascular disease, along with risk of secondary malignant neoplasms, are the most common life-threatening, long-term effects associated with platinum-based chemotherapy, ${ }^{7}$ with additional known late-effects that include abnormalities in the otologic, neurologic, and reproductive systems. ${ }^{8}$ Platinum-based chemotherapy has been associated with increased incidence of cardiovascular disease, with higherthan-expected rates of coronary disease and myocardial infarction in TCSs. ${ }^{9,10}$ Research findings suggest that chemotherapy-mediated endothelial injury and dysfunction translates into higher risk of cardiovascular disease. ${ }^{11}$ TCSs who have been treated with chemotherapy have been shown to have a 3- to 4 -fold increase in risk of developing cardiovascular disease. This increased risk in survivors has led to a call to identify interventions that can be implemented to improve morbidity and mortality. ${ }^{6}$

Platinum-based chemotherapy, however, does

Accepted for publication October 3, 2013. Correspondence: Matthew J Reilley, MD; matthew.reilley@uphs.upenn.edu. JCSO 2014;12:121-128. C2014 Frontline Medical Communications. DOI 10.12788/jcso.0033. 
not seem to be the only risk factor for cardiovascular disease in this population. Zagers and colleagues ${ }^{12}$ reported an elevated risk for cardiac event mortality in long-term follow-up in individuals treated with radiotherapy alone. Others have reported an elevated Framingham cardiovascular risk profile among TCSs regardless of treatment regimen. ${ }^{11}$

As noted by Haugnes, ${ }^{7}$ although late-effects and risks may be brought on by disease, treatment, genetic predisposition, and behavioral factors, only behavioral factors represent a clear target for later intervention. In particular, health behaviors are associated with risk reduction for cardiovascular disease and, to a lesser extent, secondary malignancies such as those associated with smoking. ${ }^{13}$ This includes behaviors that improve cardiovascular health (eg, diet and exercise) and those that avoid harm (eg, smoking cessation and moderation of alcohol use). Therefore, efforts to identify areas for risk reduction in the TCS population might benefit from concurrent efforts to understand the psychosocial barriers that inhibit optimal health behaviors.

There are a handful of studies that seek to quantify the health behaviors of TCSs. These studies have shown that survivors may be more likely to engage in problem drinking or make poor dietary choices ${ }^{14}$ and generally feel that they are not getting sufficient exercise. ${ }^{15}$ Although this work has begun to identify behaviors that may benefit from intervention, it has not specifically sought to understand the barriers that prevent TCSs from achieving optimal health behaviors.

Health-related quality of life (QOL) is a multidimensional construct that includes physical and mental health components and subjective assessments of functional, social, health, and affective status or well-being. Although quality of life is diminished in TCSs during acute treatment, the physical and mental aspects of QOL tend to rebound in the years after treatment. ${ }^{16}$ Indeed, research suggests that within a few years after treatment, physical and mental health QOL in TCSs is comparable with the physical and mental QOL of healthy controls. ${ }^{17,18}$ Although the type of treatment received (eg, chemotherapy and retroperitoneal lymph node dissection) affects QOL in the short term, these effects tend to dissipate over time, with long-term QOL being more closely related to the presence of treatment side effects and cancer-related distress. ${ }^{19}$ Moreover, health behaviors in general have been shown to be associated with QOL in both observational ${ }^{20-22}$ and interventional ${ }^{23}$ studies of cancer survivors, although these associations have not been examined in TCSs. The goal of this study was to identify health behavior patterns in a large group of TCSs, to elucidate more clearly what barriers prevent more positive health behaviors, and to examine the relationships between health behaviors, barriers to better health behavior, and QOL.

With a better understanding of which behaviors to tar- get in TCSs and of the perceived barriers to their engaging in positive health behaviors, providers will be better equipped to help survivors achieve beneficial behavioral changes.

\section{Method}

\section{Study design}

This was a cross-sectional study examining health behaviors in a state registry-based sample of TCSs. Eligibility included an adult-onset (age 18 years or older) diagnosis of testicular cancer during 1990-2005 in the state of Pennsylvania, currently living, and the self-reported ability to read and understand English.

\section{Procedure}

Recruitment occurred through the Pennsylvania Cancer Registry. Following approval from our internal review board, we requested contact information for all individuals with an ICD-O-3 code for testicular cancer (C62.0-C62.9) during 1990-2007. These data were then cross-referenced against state death records and the names of known deceased individuals were removed. Eligible individuals then received a letter that briefly explained the study and informed them that they would shortly receive consenting and questionnaire materials. These individuals were also provided with contact information to use should they have questions or wish to actively decline materials. A total of 1,054 individuals were sent materials. Of those, 169 were returned as undeliverable or because the addressee was deceased. In all, 194 packets were returned to us, of which 189 (21.4\%) provided usable data (ie, the questionnaire packet and consent form were completed).

\section{Instruments}

Demographic variables. Demographic variables were selfreported and included current age, ethnic/racial identification, marital status, educational level, income, insurance status, living situation, height and weight, and presence of chronic medical comorbidities. The respondents also answered a series of questions about their diagnoses, staging, disease history, and the treatment they received for testicular cancer. Unfortunately, accurate abstracted data on disease stage and treatment were not available from the registry.

Quality of life. QOL was assessed using the Functional Assessment of Cancer Therapy - General (FACT-G), ${ }^{24}$ which consists of 27 items assessing general quality of life domains that included physical, social/family, emotional, functional well-being, as well as a total QOL score. The FACT-G has been well validated and shown to be reliable. ${ }^{24,25}$ In addition, the 12-item Short Form Health Survey (SF-12) ${ }^{26}$ was used to assess emotional and social functioning and role limitations. This measure has been 
used extensively in various medical populations and has yielded rich normative data.

Health behaviors. Health behaviors were assessed using the battery suggested by Glasgow and colleagues. ${ }^{27}$ This 22-item measure assesses physical activity levels using the Rapid Assessment of Physical Activity, ${ }^{28}$ which assess aerobic activity and strength and flexibility in adults. Drinking behavior was assessed using items from the Behavior Risk Factor Surveillance System (BRFSS), ${ }^{29}$ which offer the ability to detect risky drinking (defined as 2 or more drinks a day on average or 5 or more drinks in one sitting in the previous 30 days), to examine changes in binge drinking, and to compare the findings with national norms. Cigarette smoking was assessed with 3 items from national health surveys that enquire about smoking history, current smoking status, and extent of smoking. Individual items are taken from national surveys ${ }^{29-31}$ and provide normative data. Eating patterns were assessed with the Starting the Conversation (STC) dietary tool, which assesses food patterns versus nutrient or fat intake and has been validated by Paxton and colleagues. ${ }^{32}$ This 8 -item measure has values that range from $0-16$, with lower scores indicating healthier diet.

Barriers to health care behaviors. Barriers to health care behaviors were assessed using a newly created measure. Seventeen TCSs who were recruited from an in-house clinic completed qualitative semistructured interviews before information saturation was reached. Those who completed interviews were white and non-hispanic. Their age range was 21-53 years, with a mean age of of 38.6 years (standard deviation [SD], 7.8). Time since diagnosis ranged from 2.1 to 14.2 years (mean, 4.9 years [SD, 3.8]). Participants were paid $\$ 20$ for participation. Themes derived from the interview data were then used to construct items reflecting attitudes and beliefs concerning health behaviors. Items were reviewed for clarity and completeness by the investigator team until consensus was reached. The resulting initial scale to be examined contained 48 items. Potential items with predominately negative correlations across other items were then reverse scaled.

Next we performed an initial evaluation by examining the corrected item-total score correlations. Items that correlated to the corrected scale at a value of $<0.30$ were eliminated. The remaining 19 items were subjected to principle axis factoring. Examination of the scree plot suggested a 3-factor solution. However, the third factor produced an eigenvalue of less than 1.0, so a 2 -factor solution was examined. Factors were then reproduced and rotated using Promax rotation with Kaiser normalization. Rotated items with clean characteristics (ie, loadings of greater than 0.4 on the primary factor and less than 0.3 on the secondary factor) were retained. This dropped the number of items to 10. Reanalysis using the same parameters suggested this 2 -factor solution to be a good fit to the data that accounted for $40 \%$ of the variance in items. The 2 extracted factors were examined and named Cancer-related Barriers (CB; 6 items) and Competing Demands (CD; 4 items). Cronbach's alpha was calculated for each subscale and was adequate for both Cancer-related Barriers (alpha $=0.75)$ and Competing Demands (alpha $=0.78$ ). Scale totals are averaged such that $1=$ definitely false and $5=$ definitely true, reflecting greater endorsement of barriers.

\section{Statistical analysis}

Analyses included descriptive statistics, independent group t-tests, Pearson product-moment correlation coefficients, and analysis of variance as appropriate. Multivariate analyses were not performed because our goals were exploratory and bivariate rather than focused on a priori model testing. Model testing in the absence of a priori theorized relationships is known to capitalize on chance, to present a risk of over-fitting the available data, and to produce unreliable estimates $^{33}$ All of the statistical analyses were performed using IBM SPSS 20.0..$^{34}$

\section{Results}

The study sample was predominately white, middle aged, married or living in a marriage-like situation, college educated, and working (Table 1). Self-reported disease variables suggested a lack of knowledge of staging and type of tumor. Overall, more than two-thirds of the sample reported receipt of orchiectomy, about half reported radiation treatment, and slightly less than a third reported exposure to chemotherapy. Health-related QOL was similar to that of the general population norms on the SF-12 for the Mental (mean, 50.23 [SD, 9.58]) and Physical components (mean, 52.30 [6.54]; normative mean 50 [SD, 10]), as seen in Table 2. Cancer-specific QOL on the FACT-G was also similar to or slightly higher than normative values for Physical Well-being (mean, 25.58 [3.17]; normative mean, 23.3), Emotional Well-being (mean, 20.10 [5.70]; normative mean, 20.5), Social Well-being (mean, 21.09 [2.95]; normative mean, 18.4), and Functional Well-being (mean, 21.76 [5.33]; normative mean, 18.6) subscales, as well as the Total QOL score (mean, 88.47 [13.66]; normative mean, 80.9).

Participants reported high levels of current tobacco use (including smoking and smokeless use), with almost $25 \%$ reporting current use (Table 3 ). Similarly, more than a third reported alcohol behaviors that place them in the "risky drinking" category. Diet demonstrated substantial room for improvement (mean, 7.33). Of particular interest, $95 \%$ of the respondents reported inadequate fruit and vegetable intake, $43 \%$ reported 3 or more sweetened beverages a day, and 58\% reported more than 1 fastfood meal a week. Although adequate levels of aerobic activity were reported 


\begin{tabular}{|c|c|}
\hline $\begin{array}{l}\text { TABLE } 1 \text { Characteristics of respondents } \\
\text { Characteristic }\end{array}$ & $\begin{array}{l}\text { No. of } \\
\text { respondents (\%) } \\
(\mathbf{N}=189)\end{array}$ \\
\hline Age, mean (SD), y: 43.62 (9.86) & - \\
\hline $\begin{array}{l}\text { Time since diagnosis, } \\
\text { mean (SD), y: } 6.78 \text { (3.78) }\end{array}$ & - \\
\hline $\begin{array}{l}\text { Race } \\
\text { White } \\
\text { Other }\end{array}$ & $\begin{array}{rr}180 & (95.2) \\
9 & (4.8)\end{array}$ \\
\hline $\begin{array}{l}\text { Marital status } \\
\text { Married/marriage-like } \\
\text { Widowed } \\
\text { Separated/divorced } \\
\text { Single }\end{array}$ & $\begin{array}{rr}136 & (72) \\
1 & (0.5) \\
15 & (7.9) \\
37 & (19.6)\end{array}$ \\
\hline $\begin{array}{l}\text { Paternity } \\
\text { Yes }\end{array}$ & $129(68.6)$ \\
\hline $\begin{array}{l}\text { Education } \\
\leq \text { High school } \\
\text { Some college/trade } \\
\geq \text { College degree }\end{array}$ & $\begin{array}{l}42(22.2) \\
36(19) \\
111(58.7)\end{array}$ \\
\hline $\begin{array}{l}\text { Current employment } \\
\text { Full-time } \\
\text { Part-time } \\
\text { Unemployed } \\
\text { Retired/student/disabled }\end{array}$ & $\begin{aligned} 150 & (79.4) \\
13 & (6.9) \\
9 & (4.8) \\
17 & (9)\end{aligned}$ \\
\hline $\begin{array}{l}\text { Self-reported tumor type } \\
\text { Seminoma } \\
\text { Nonseminoma } \\
\text { Mixed } \\
\text { Unknown }\end{array}$ & $\begin{array}{r}99(54) \\
28(15) \\
4(2) \\
47(26)\end{array}$ \\
\hline $\begin{array}{l}\text { Self-report disease stage } \\
\text { I } \\
\text { II } \\
\text { II } \\
\text { Not known }\end{array}$ & $\begin{array}{l}78(42) \\
28(15) \\
18(10) \\
58(32)\end{array}$ \\
\hline $\begin{array}{l}\text { Self-reported treatments } \\
\text { Orchiectomy } \\
\text { RPLND } \\
\text { Radiotherapy } \\
\text { XRT }\end{array}$ & $\begin{array}{l}126(69) \\
34(19) \\
58(32) \\
97(53)\end{array}$ \\
\hline $\begin{array}{l}\text { RPLND, retroperitoneal lymph node dissection } \\
\text { therapy }\end{array}$ & XRT, radiation \\
\hline
\end{tabular}

by half the participants, only slightly more than a quarter reported adequate participation in both strength-training and flexibility-related leisure time activities. Overall, 83.5\% of the sample reported BMI levels that were higher than the normal range, with more than one-third falling into the obese range. Participants were more likely to endorse Competing Demands (mean, 2.42) than Cancer-related Barriers (mean, 1.53; $\mathrm{t}=10.90, \mathrm{P}<.001$ ).

\section{Health behaviors, barriers, and quality of life}

We first examined relationships between health behaviors and demographic variables. Individuals with risky drinking behavior were younger (mean, 40.4 years [9.40]) than those with no risky behavior (mean, 45.5 years $[10.01] ; \mathrm{F}(1,186)$ $=11.12, \mathrm{P}<.001)$, and BMI was related to age $(\mathrm{r}=.19$, $\mathrm{P}=.01)$. Relationships between age, race, marital status, education, job status, and other health behaviors were all nonsignificant. Table 2 shows the relationships between health behaviors and indices of QOL. Tobacco and alcohol use were not related to any indices of QOL. However, adequate aerobic exercise was significantly related to a better QOL for all indices except the SF-12 Physical Health component score and the Social Well-being subscale of the FACT-G. Adequate strength and flexibility exercise predicted better QOL in all indices except the SF-12 Mental Health component. Poorer dietary intake predicted lower QOL in all indices except the SF-12 Physical Health component score, which was also the only QOL measure inversely associated with higher BMI.

Neither Cancer-related Barriers (CB) nor Competing Demands (CD) were related to age, race, marital status, education, paternity, or time since diagnosis (all $\mathrm{P}>.20$ ). There was a significant relationship between $\mathrm{CB}$ and current employment status, such that individuals who were employed fulltime reported fewer CB (mean, 1.46 [0.60]) relative to those who were not employed fulltime (mean, $1.80[0.75] ; \mathrm{F}(1,181)=3.22, \mathrm{P}=.005)$. This relationship was not found for CD. Table 4 shows the relationships between $\mathrm{CB}, \mathrm{CD}$, and health behaviors/QOL. As can be seen, $\mathrm{CB}$ related to worse physical functioning on the SF-12, worse QOL in all aspects of the FACT-G, and higher BMI. CD were predictive of worse psychosocial functioning on the SF-12, decreased QOL on all FACT-G scales, more unhealthy eating patterns, decreased leisure time physical activity, and a greater chance of performing inadequate aerobic as well as strength and flexibility physical activities. Neither scale related to smoking or drinking behaviors as assessed in the current study.

\section{Discussion and conclusions}

To the best of our knowledge, this is the first examination of barriers to health behaviors among survivors of testicular cancer. As these patients transition to survivorship, their primary health concerns move from acute oncologic treatment to prevention and remediation of long-term and late effects of disease and treatment. Addressing health behaviors with survivors may present an opportunity for providers to minimize long-term negative effects of therapy. The results of this work highlight heterogeneity among the barriers to optimal healthy behaviors. Although TCSs experience clear cancerrelated barriers, competing demands seem to play a larger role limiting their health behaviors. Our work highlights several barriers to practicing positive health behaviors that providers can target. Specifically, targeting interventions to address patient-perceived barriers is likely to result in beneficial longterm improvements in health. 


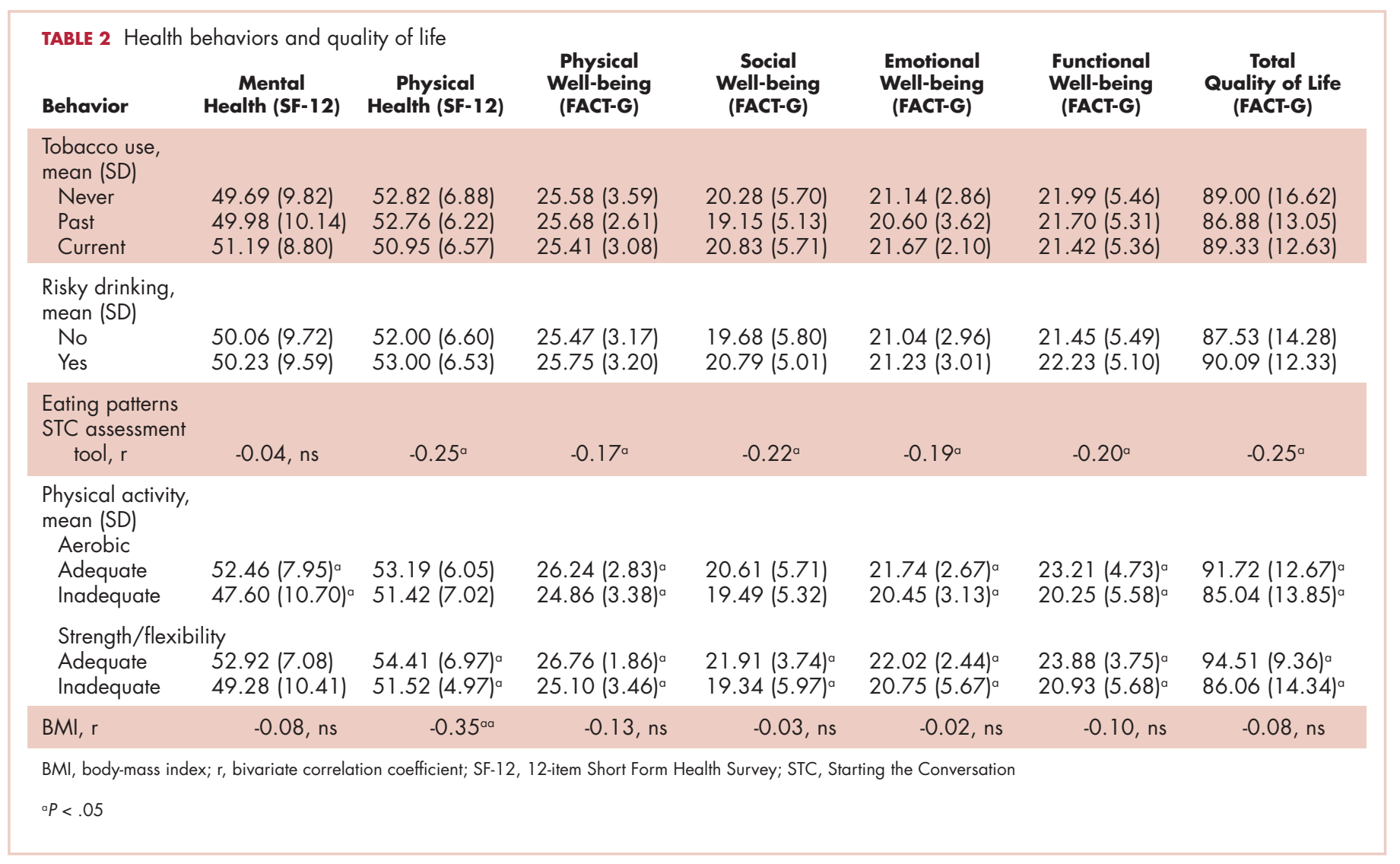

About half of our sample reported adequate aerobic exercise. That approximates to the national $52.1 \%$ rate of aerobic exercise in working-age men reported by the Centers for Disease Control. ${ }^{35}$ Similarly, 28\% of the study population reported adequate strength and flexibility, compared with the national rate of $29.1 \%{ }^{35}$ There is currently a lack of specific interventions for TCSs. However, there are more general strategies for encouraging exercise in cancer survivors. ${ }^{36}$ These include working to increase provider awareness of the importance of posttreatment exercise and making increased physical activity part of the treatment plan. Timing is also important: a study among Norwegian cancer survivors showed that young men who received chemotherapy were the most interested in receiving counseling and/or education about exercise and that they wanted to start immediately after finishing treatment. ${ }^{37}$

Tobacco use among this sample of TCSs was close to the national average for similarly aged men. ${ }^{38}$ This is consistent with findings from previous studies, ${ }^{39}$ but somewhat higher than other examinations of smoking behaviors among TCSs. ${ }^{14}$ The link between cardiovascular disease and smoking is well established. ${ }^{40}$ Given the increased risk of cardiovascular disease among TCSs ${ }^{11}$ that finding takes on added importance. Research findings suggest that cancer survivors are more likely to quit smoking if they are men and if their cancer diagnosis was not related to smoking. ${ }^{41}$
This implies that TCSs may be more amenable to intervention than are other groups, and further research into tailoring smoking cessation therapies to TCSs is needed. It is noteworthy that work by Shinn and colleagues found that smoking in TCSs correlated with depression, ${ }^{42}$ which suggests that particular attention should be paid to screening TCS smokers for depression and providing appropriate treatment for depression because it may increase likelihood of tobacco cessation.

Our data also suggest that although exercise levels and dietary intake are related to many aspects of QOL, TCSs are limited by competing demands (eg, time, work). Moreover, these barriers to positive health behaviors relate to poorer mental health QOL, poorer dietary choices, and a greater likelihood of inadequate exercise. Similarly, participants with greater cancer-related barriers had worse physical QOL and a higher BMI. There is good evidence that regular and/or highintensity exercise can improve QOL and lower the BMI..$^{15,43}$ Higher levels of physical activity are also associated with lower levels of depression and lower levels of tobacco use. Thus, one way to address QOL may be to encourage higher levels of exercise for TCSs. Our results suggest that although some survivors may need support for cancer-related limitations to improve physical QOL, competing demands play a more profound role in health behaviors. This may not be surprising given the relatively young age and high level of education 
TABLE 3 Prevalence and assessments of health behavior and barriers to health care behaviors

\section{Behavior or barrier}

$\begin{array}{ll}\text { Tobacco use (BRFSS), } & \\ \text { no. of survivors (\%) } & \\ \text { Never } & 83(43.9) \\ \text { Past } & 59(31.2) \\ \text { Current } & 47(24.9)\end{array}$

\begin{tabular}{|c|c|}
\hline $\begin{array}{l}\text { Current risky drinking (BRFSS), } \\
\text { no. of survivors (\%) } \\
\text { No } \\
\text { Yes }\end{array}$ & $\begin{array}{r}123(65.1) \\
66(34.9)\end{array}$ \\
\hline $\begin{array}{l}\text { Eating patterns, mean (SD) } \\
\text { STC assessment tool }\end{array}$ & $7.33(2.62)$ \\
\hline $\begin{array}{l}\text { Physical activity } \\
\text { RAPA, no. of survivors (\%) } \\
\text { Adequate aerobic exercise } \\
\text { Adequate strength/flexibility }\end{array}$ & $\begin{array}{l}95(50.3) \\
53(28)\end{array}$ \\
\hline $\begin{array}{l}\text { BMl range, no. of survivors (\%) } \\
\text { Below normal } \\
\text { Normal } \\
\text { Obese }\end{array}$ & $\begin{array}{c}0(0) \\
35(18.5) \\
88(48.6)\end{array}$ \\
\hline
\end{tabular}

Barriers to health behaviors, mean (SD)

$\begin{array}{ll}\text { Competing Demands } & 2.42(1.00) \\ \text { Cancer-Related }^{b} & 1.53(0.65)\end{array}$

BMI, body-mass index; BRFSS, Behavioral Risk Factor Surveillance System; Godin LTE, Godin Leisure-Time Exercise Questionnaire; RAPA, Rapid Assessment of Physical Activity; STC, Starting the Conversation

aSTC range $=0-16$, with higher values representing worse dietary habits bFor both Competing Demands and Cancer-Related, 1 = definitely false and $5=$ definitely true, with higher scores reflecting greater endorsement of barriers. Normative values are the values reflected in this publication. This is scale is newly designed/validated for this publication.

and employment of this sample. Overcoming these barriers is likely to require a multifaceted approach that can work within the time and energy constraints of a busy group of survivors. For example, a study with breast cancer survivors found that involving survivors in 3 day-long workshops led to significantly increased knowledge of their disease and a significant increase in exercise levels at 6 months, compared with controls. ${ }^{44}$ Evidence also suggests that education in time management and positive reinforcement can help improve survivor adherence to regular exercise. ${ }^{45}$ These interventions have the potential to improve health behavior adherence and deserve further investigation in the TCS population.

In our study sample, QOL scores were similar to or even slightly higher than one would find in non-TCS populations. ${ }^{46-48}$ At the same time, rates of elevated BMI, poor diet, smoking, risky alcohol use, and inadequate physical activity were rather high, particularly considering the elevated risk of cardiovascular disease in this population. TCSs seem to be relatively well functioning and healthy men who can expect to live 40 to 50 years after treatment ${ }^{7}$ but they are often remiss about participating in positive health care behaviors. Given their high level of physical and emotional functioning, life expectancy, and risks for cardiovascular disease, they might be more willing and able than many members of the general population to act on recommendations for improving health behaviors if that were made a priority by their treatment providers. It is critical to educate TCSs about the health risks associated with their treatment as well as the positive health behaviors that could improve their overall health and QOL.

Our study suggests that reducing or working within the competing demands of these men's busy lives may also be necessary to help them affect change. As noted by Haugnes and colleagues, ${ }^{7}$ health behaviors and lifestyle factors are among the few cardiovascular risk factors that are amenable to change in this population. These should be made a focus in survivorship care.

This study is not without limitations. The sample, although the largest to date that specifically examines health behaviors among TCSs, is modest in size. Moreover, the relatively low response rate may imply difficulties in generalization because of self-selection. We note, however, that this was likely a more diverse and representative sample than would have been obtained had we recruited patients from a single institution. Health behaviors were assessed through self-report rather than more observational or standardized means (eg, daily food diaries). This is a common practice in the literature and allows for comparisons between our sample and those of other investigators. The tool for assessment of barriers to health behaviors is new and has only been used in this sample to date. Additional validation work needs to be completed before definitive statements can be about results using this measure. Although significant associations and differences were described, the effect sizes were modest. For example, the largest correlation reported suggests that less than 13\% of variance is shared between BMI and Physical Health on the SF-12. This implies that other factors are likely playing a role in QOL. Finally, given that this was a state registrybased sample, information on abstracted disease and treatment was not available. In addition, patient reports of their disease and treatment information may not be reliable. ${ }^{49}$ For example, nearly a third of participants did not know their initial disease staging.

Given the negative health behaviors prevalent in this sample and the risk for cardiovascular long-term and late effects of treatment, interventions are needed to reduce tobacco and risky alcohol use and improve dietary and physical activity. Interventions should be targeted to address the most relevant barriers, such as the competing demands of adult life among a compromised population as well as cancer-related limitations. Further investigation is needed into specific behavior-related barriers and to identify specific interventions to address them. 
TABLE 4 Quality of life, health behaviors, and barriers to health behaviors ${ }^{a}$

\begin{tabular}{|c|c|c|}
\hline & $\begin{array}{c}\text { Cancer-related } \\
\text { barriers }\end{array}$ & $\begin{array}{l}\text { Competing } \\
\text { demands }\end{array}$ \\
\hline $\begin{array}{l}\text { Quality of life, } r \\
\text { Mental Health (SF-12) } \\
\text { Physical Health (SF-12) } \\
\text { Physical Well-being (FACT-G) } \\
\text { Social Well-being (FACT-G) } \\
\text { Emotional Well-being (FACT-G) } \\
\text { Functional Well-being (FACT-G) } \\
\text { Total Quality of Life (FACT-G) }\end{array}$ & $\begin{array}{l}-0.14 \\
-0.49^{b} \\
-0.58^{b} \\
-0.20^{b} \\
-0.31^{b} \\
-0.45^{b} \\
-0.46^{b}\end{array}$ & $\begin{array}{l}-0.33^{b} \\
-0.14^{1} \\
-0.29^{b} \\
-0.26^{b} \\
-0.26^{b} \\
-0.27^{b} \\
-0.30^{b}\end{array}$ \\
\hline $\begin{array}{l}\text { Tobacco use, mean (SD) } \\
\text { Never } \\
\text { Past } \\
\text { Current }\end{array}$ & $\begin{array}{c}\mathrm{F}_{(2,180)}=0.24, \mathrm{~ns} \\
1.54(0.68) \\
1.47(0.60) \\
1.56(0.65)\end{array}$ & $\begin{array}{c}\mathrm{F}_{(2,180)}=1.70, \mathrm{~ns} \\
2.53(1.06) \\
2.45(0.96) \\
2.20(0.95)\end{array}$ \\
\hline $\begin{array}{l}\text { Risky drinking, mean (SD) } \\
\text { No } \\
\text { Yes }\end{array}$ & $\begin{array}{c}\mathrm{F}_{(1,181)}=0.44, \mathrm{~ns} \\
1.50(0.58) \\
1.57(0.75)\end{array}$ & $\begin{array}{l}\mathrm{F}_{(1,181)}=1.80, \mathrm{~ns} \\
2.50(1.02) \\
2.38(0.99)\end{array}$ \\
\hline $\begin{array}{l}\text { Eating patterns, } r \\
\text { STC assessment tool }\end{array}$ & 0.04 & $0.29^{a}$ \\
\hline $\begin{array}{l}\text { Physical activity, mean (SD) } \\
\text { Aerobic } \\
\text { Adequate } \\
\text { Inadequate }\end{array}$ & $\begin{array}{c}\mathrm{F}_{(1,181)}=1.95, \mathrm{~ns} \\
1.46(0.64) \\
2.07(0.92)\end{array}$ & $\begin{array}{l}F_{(1,181)}=25.29 b \\
1.60(0.65) \\
2.77(0.97)\end{array}$ \\
\hline $\begin{array}{l}\text { Strength/flexibility } \\
\text { Adequate } \\
\text { Indequate }\end{array}$ & $\begin{array}{c}\mathrm{F}_{(1,181)}=2.54, \mathrm{~ns} \\
1.40(0.55) \\
1.58(0.68)\end{array}$ & $\begin{array}{l}\mathrm{F}_{(1,181)}=29.47 \mathrm{~b} \\
1.83(0.69) \\
2.66(1.02)\end{array}$ \\
\hline Body-mass index, $r$ & $0.16^{b}$ & 0.06 \\
\hline
\end{tabular}

\section{References}

1 American Cancer Society. Cancer Facts \& Figures 2013. Atlanta, Georgia: American Cancer Society; 2013.

2 N. Howlader, A. Noone, M. Krapcho, et al (eds). SEER Cancer Statistics Review, 1975-2009 (Vintage 2009 Populations). Bethesda, Maryland: National Cancer Institute; 2012.

3. Haugnes HS, Aass N, Fosså SA, et al. Predicted cardiovascular mortality and reported cardiovascular morbidity in testicular cancer survivors. J Cancer Surviv Res Pract. 2008;2:128-137.

4. Fosså SD, Aass N, Harvei S, Tretli S. Increased mortality rates in young and middle-aged patients with malignant germ cell tumours. Br J Cancer. 2004;90:607-612.

5. Abouassaly R, Fossa SD, Giwercman A, et al. Sequelae of treatment in long-term survivors of testis cancer. Eur Urol. 2011;60:516-526.

6. Travis LB, Beard C, Allan JM, et al. Testicular cancer survivorship: research strategies and recommendations. J Natl Cancer Inst. 2010;102:1114-1130.

7. Haugnes HS, Bosl GJ, Boer H, et al. Long-term and late effects of germ cell testicular cancer treatment and implications for follow-up. J Clin Oncol. 2012;30:3752-3763.

8. Strumberg D, Brügge S, Korn MW, et al. Evaluation of long-term toxicity in patients after cisplatin-based chemotherapy for non-seminomatous testicular cancer. Ann Oncol. 2002;13:229-236.

9. Meinardi MT, Gietema JA, Van Der Graaf WT, et al. Cardiovascular morbidity in long-term survivors of metastatic testicular cancer. J Clin Oncol. 2000;18:1725-1732.

10. Huddart RA, Norman A, Shahidi M, et al. Cardiovascular disease as a long-term complication of treatment for testicular cancer. J Clin Oncol. 2003;21:1513-1523.
11. Vaughn DJ, Palmer SC, Carver JR, Jacobs LA, Mohler ER. Cardiovascular risk in long-term survivors of testicular cancer. Cancer. 2008;112:1949-1953.

12. Zagars GK, Ballo MT, Lee AK, Strom SS. Mortality after cure of testicular seminoma. J Clin Oncol. 2004;22:640-647.

13. van den Belt-Dusebout AW, de Wit R, Gietema JA, et al. Treatment-specific risks of second malignancies and cardiovascular disease in 5-year survivors of testicular cancer. J Clin Oncol. 2007;25:4370-4378.

14. Shinn EH, Swartz RJ, Thornton BB, Spiess PE, Pisters LL, BasenEngquist KM. Testis cancer survivors' health behaviors: comparison with age-matched relative and demographically matched population controls. J Clin Oncol. 2010;28:2274-2279.

15. Thorsen L, Nystad W, Dahl O, et al. The level of physical activity in long-term survivors of testicular cancer. Eur J Cancer. 2003;39:1216-1221.

16. Vidrine DJ, Hoekstra-Weebers JE, Hoekstra HJ, Tuinman MA, Marani S, Gritz ER. The effects of testicular cancer treatment on health-related quality of life. Urology. 2010;75:636-641.

17. Rossen PB, Pedersen AF, Zachariae R, von der Maase H. Healthrelated quality of life in long-term survivors of testicular cancer. J Clin Oncol. 2009;27:5993-5999.

18. Fosså SD, Oldenburg J, Dahl AA. Short- and long-term morbidity after treatment for testicular cancer. BJU Int. 2009;104:1418-1422.

19. Mykletun A, Dahl AA, Haaland CF, et al. Side effects and cancerrelated stress determine quality of life in long-term survivors of testicular cancer. J Clin Oncol. 2005;23:3061-3068.

20. Mosher CE, Sloane R, Morey MC, et al. Associations between lifestyle factors and quality of life among older long-term breast, pros- 
tate, and colorectal cancer survivors. Cancer. 2009;115:4001-4009.

21. Beesley VL, Eakin EG, Janda M, Battistutta D. Gynecological cancer survivors' health behaviors and their associations with quality of life. Cancer Causes Control. 2008;19:775-782.

22. Penedo FJ, Dahn JR, Shen BJ, Schneiderman N, Antoni MH. Ethnicity and determinants of quality of life after prostate cancer treatment. Urology. 2006;67:1022-1027.

23. Bowen DJ, Powers D. Effects of a mail and telephone intervention on breast health behaviors. Health Educ Behav. 2010;37:479-489.

24. Cella DF, Tulsky DS, Gray G, et al. The Functional Assessment of Cancer Therapy scale: development and validation of the general measure. J Clin Oncol. 1993;11:570-579.

25. Winstead-Fry P, Schultz A. Psychometric analysis of the Functional Assessment of Cancer Therapy-General (FACT-G) scale in a rural sample. Cancer. 1997;79:2446-2452.

26. Ware JE, Gandek B. Methods for testing data quality, scaling assumptions, and reliability: the IQOLA Project approach. International Quality of Life Assessment. J Clin Epidemiol. 1998;51:945-952.

27. Glasgow RE, Ory MG, Klesges LM, Cifuentes M, Fernald DH, Green LA. Practical and relevant self-report measures of patient health behaviors for primary care research. Ann Fam Med. 2005;3:73-81.

28. University of Washington Health Promotion Research Center. Rapid Assessment Physical Activity Scale (RAPA). 2004

29. Centers for Disease Control and Prevention (CDC). Behavioral Risk Factor Surveillance System Survey Questionnaire. 2004.

30. Ory MG, Jordan PJ, Bazzarre T. The Behavior Change Consortium: setting the stage for a new century of health behavior-change research. Health Educ Res. 2002;17:500-511.

31. Shiffman S, West R, Gilbert D, SRNT Work Group on the Assessment of Craving and Withdrawal in Clinical Trials. Recommendation for the assessment of tobacco craving and withdrawal in smoking cessation trials. Nicotine Tob Res. 2004;6:599-614.

32. Paxton AE, Strycker LA, Toobert DJ, Ammerman AS, Glasgow RE. Starting the conversation performance of a brief dietary assessment and intervention tool for health professionals. Am J Prev Med. 2011;40:67-71.

33. Babyak MA. What you see may not be what you get: a brief, nontechnical introduction to overfitting in regression-type models. Psychosom Med. 2004;66:411-421.

34. IBM Corp. Released 2011. IBM SPSS Statistics for Windows, Version 20.0. Armonk, NY: IBM Corp.

35. Health, United States, 2011: With Special Feature on Socioeconomic
Status and Health. Hyattsville, Maryland:National Center for Health Statistics (US); 2012. Report No:2012-1232.

36. Irwin ML. Physical activity interventions for cancer survivors. Br J Sports Med. 2009;43:32-38.

37. Gjerset GM, Fosså SD, Courneya KS, Skovlund E, Jacobsen AB, Thorsen L. Interest and preferences for exercise counselling and programming among Norwegian cancer survivors. Eur J Cancer Care (Engl). 2011;20:96-105.

38. American Lung Association. Trends in Tobacco Use. Washington, DC; 2011.

39. Mayer DK, Carlson J. Smoking patterns in cancer survivors. Nicotine Tob Res. 2011;13:34-40.

40. Price JF, Mowbray PI, Lee AJ, Rumley A, Lowe GD, Fowkes FG. Relationship between smoking and cardiovascular risk factors in the development of peripheral arterial disease and coronary artery disease: Edinburgh Artery Study. Eur Heart J. 1999;20:344-353.

41. Schnoll RA, Martinez E, Langer C, Miyamoto C, Leone F. Predictors of smoking cessation among cancer patients enrolled in a smoking cessation program. Acta Oncol. 2011;50:678-684.

42. Shinn EH, Basen-Engquist K, Thornton B, Spiess PE, Pisters L. Health behaviors and depressive symptoms in testicular cancer survivors. Urology. 2007;69:748-753.

43. De Backer IC, Van Breda E, Vreugdenhil A, Nijziel MR, Kester AD, Schep G. High-intensity strength training improves quality of life in cancer survivors. Acta Oncol. 2007:46:1143-1151.

44. Bloom JR, Stewart SL, D’Onofrio CN, Luce J, Banks PJ. Addressing the needs of young breast cancer survivors at the 5 year milestone: can a short-term, low intensity intervention produce change? J Cancer Surv. 2008;2:190-204.

45. Rogers LQ Vicari S, Courneya KS. Lessons learned in the trenches: facilitating exercise adherence among breast cancer survivors in a group setting. Cancer Nurs. 2010;33:E10-E17.

46. Fleer J, Hoekstra HJ, Sleijfer DT, Tuinman MA, Klip EC, HoekstraWeebers JE. Quality of life of testicular cancer survivors and the relationship with sociodemographics, cancer-related variables, and life events. Support Care Cancer. 2006;14:251-259.

47. Dahl AA, Mykletun A, Fosså SD. Quality of life in survivors of testicular cancer. Urol Oncol. 2005;23:193-200.

48. Joly F, Héron JF, Kalusinski L, et al. Quality of life in long-term survivors of testicular cancer: a population-based case-control study. J Clin Oncol. 2002;20:73-80.

49. Nissen MJ, Tsai ML, Blaes AH, Swenson KK. Breast and colorectal cancer survivors' knowledge about their diagnosis and treatment. J Cancer Surviv. 2012;620-32. 